\title{
La religión tradicional entre los aymaras de Arica
}

\author{
Patricio Tudela
}

La Cosmovisión entre los aymaras de Arica.

El estudio de la cosmovisión aymara ha sido emprendido por diversos investigadores en

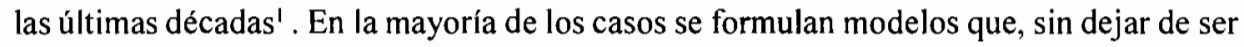
útiles por la información que presentan, describen una realidad supuestamente universal. Esto es importante, pues se habla en términos globales y se olvida el hecho de que la concepción del mundo, como todo fenómeno cultural, tiene variaciones locales-regionales y generacionales, por mencionar algunas. Hasta hoy no hay estudios sobre las alteraciones en la cosmovisión como efecto de los cambios tecnológicos (modernización), sociales (escuela chilena y penetración de las sectas evangélicas) y ecológicos que están ocurriendo. Este es un aspecto urgente a investigar que debe ser tomado en cuenta.

Los aymaras más tradicionalistas, aquellos de la cordillera y altiplano de Arica (Putre, Belén, Guallatire, Caquena y Chapiquiña) conciben el cosmos -desde una perspectiva vertical- como conformado por tres niveles o zonas: El A rajpacha, el Taypipacha y el Manqhapacha. Estas zonas, en el caso de los menos tradicionales, son asociadas con el cielo (arriba), la tierra (nosotros), y el infierno (debajo de la tierra).

\section{El. ARA.JPACHA.}

El Arajpacha identifica lo que está arriba, sobre el hombre, en el cielo. Es el mundo superior. Allí habitan los espíritus que tienen un carácter benévolo. Este es el lugar del „Dios Supremo“, del „Dios Creador", de „Tatita Dios", „Tata-inti“ o „Santísimo“, cuya esposa es la „Virgen“, ,Mamaphaxsi“" (Señora Luna) o „Mamita Concepción“. También se encuentran allí las estrellas, hijos del sol y de la luna, que al mismo tiempo son „las almas de los difuntos buenos“ o,,angeles“. Allí también están los ,,santos“.

Los seres del Arajpacha asumen formas y nominaciones particulares que varían de un individuo a otro, y de una localidad a otra. Por ejemplo, la asociación entre la Virgen de la Concepción y la luna es frecuente en Carangas (Monast, 1972, p. 53). Esta, sin embargo,

\footnotetext{
'Entre los más relevantes que tratan sobre la cosınovisión aymara cabe destacar los trabajos da Albó (1991), Grebe (1981, 1990), Harris \& Bouysse (1988), Jorda (1985), Kessel (1980 y 1996), Llanque (1985, 1992), Montes (1984 y 1986), Ochoa (1978) y Berg ( $1989 \mathrm{a})$
} 
no se observa en Pacajes -más al norte- o en Caquena, tampoco en la cordillera o sectores más bajos, donde se usa la expresión „Mamaluna“ o „Virginluna“.

En el sector estudiado se identifica con claridad cuatro categorías de espíritus: a)

Dios-Padre-Sol-Masculino, b) Virgen-Madre-Luna-Femenino, c) Angel-Hijo-Estrella y d) los Santos. Las categorías a, b y c parecen tener una relación muy distante con el individuo. Ellos tienen control sobre el transcurso regular del tiempo, sin tener mayor ingerencia en la vida del hombre: „ellos están allí, no hacen nada, hay que respetarlos, dan la vida, son buenos" (SG2).

No sucede lo mismo con los Santos. Estos son más cercanos al hombre, pues, aunque están en el Arajpacha, también están en la comunidad, en la iglesia. Por esa razón le hacen fiestas y rogativas. Los santos tienen poder en el „mundo del hombre“ (Taypipacha). Entre los santos que más destacan están San Santiago, San Juan, San Andrés y San Isidro.

San Santiago, cuya festividad se celebra el 25 de Julio, es el Patrono del pueblo de Belén, antigua sede de la Doctrina de los Altos de Arica (1777). Este santo tiene devotos y seguidores en toda la región. Su popularidad se explica porque es también el Patrono de todos los poblados más importantes. También es muy popular en Carangas (Monast, 1972, p. 45) y diversas regiones del Perú y de Bolivia. Esto es resultado de "una evangelización dirigida". Se le identifica con la divinidad andina Illapa, antigua deidad que se manifiesta en el rayo y el trueno (Yaranga, 1979, p. 697-720). pero también se le mira con temor, pues se le atribuye poder sobre lluvias y granizos. Los aymaras asocian este santo con el rayo. San Santiago acompaña a la Virgen Patrona.

San Andrés es también un santo „dificil“. En Belén y Pachama se piensa que „,controla las lluvias“. Esto se debe a la fecha de su celebración, el 30 de Noviembre. Ya en Diciembre comienzan las Iluvias estivales que aseguran una buena cosecha. Una celebración no adecuada causaría la tardanza o escasez de las lluvias, lo que afecta directamente los cultivos, por esta razón se le atribuye ese carácter.

San Juan es un santo muy popular en la zona de Arica. El es responsable las crías del ganado ovino, es el Patrono de los corderos. Se le recuerda el 24 de Junio, en la fiesta de las ovejas o „floreo“. San Isidro (Labrador), por otra parte, es el santo de los agricultores o „chacareros“2 . Hay también otros santos y virgenes -como San Felipe, San José, la Candelaria, la Virgen Asunta, Santa Rosa o la Virgen del Rosario- los que, debido al calendario santoral y devoción de los misioneros ${ }^{3}$, son Patrones de los pueblos, estancias y caseríos. Entre los caserios de Guallatire, por ejemplo, San Antonio es un santo bastante importante; este reemplaza en su función a San Juan (Patrono de las ovejas) ${ }^{4}$.

\footnotetext{
${ }^{2}$ En Guallatire uno de los informantes explicó que este santo es .,el santo de los escolares, de los estudiantes“, luego dijo: „porque por algo el santo tiene un libro en la mano!" (SG5) (el santo fue Doctor de la Iglesia). Esto es un buen ejemplo de la forma de razonar, y de una reinterpretación de elementos a través de un cambio de función.

${ }^{1}$ Un buen ejemplo de la influencia de los misioneros en la devoción y preferencia por una imagen es el caso de Fray Vicente Bernedo, misionero en el altiplano del Alto Perú (Potosí), en el siglo XVII, ver Farelly (1972, p. 405-406) y Romero (1989, p. 540553).

+ La popularidad de San Antonio y su relación con las ovejas parece restringirse a la región de Sabaya-Carangas y sus alrededores (Monast, 1972, p. 64). Guallatire, aledaño a Sabaya, es la única localidad, en el sector de Arica, donde San Antonio se presenta con „más fuerza“. En Caquena y el resto de la zona San Juan es el santo de los corderos. Esto es muy interesante, porque plantea la pregunta sobre los focos de evangelización. Este vínculo de Guallatire con Sabaya está reforzado, además, por la asociación de la luna con la Virgen de la Concepción, lo que también se presenta sólo en la región de Curahuara-Carangas (Monast, 1972, p.53). Esto demostraria que, si suponemos que la devoción por un santo nace tanto del interés del ayınara como de los ınisioneros, la evangelización del sector de Guallatire dependió en los primeros años de la parroquia oriental de Bolivia y no de Arica. De ser efectiva esta hipótesis, podríamos tener aqui, entonces, un elemento importante para estudiar la relación en el siglo XVI de las localides del actual altiplano chileno con las del sector boliviano.
} 
El. MANQHAPACHA

El Manqhapacha es „el mundo de abajo", dentro de la tierra, mundo que no se ve. pero que se supone habitado por seres como el Sirinu. el Supaya, el Tío, el Amaru (katari) y los condenados.

El Sirinu o „sereno“ es un espiritu que habita en lugares donde corre el agua, vertientes y manantiales, haciendo un ruido (golpe del agua en las piedras). Por esto se le asocia con la música. Este espíritu es importante en toda celebración. En la víspera de cada festividad los músicos se reunen y encienden velas, ch'allan ${ }^{5}$ y phawa $^{6}$ en honor al Sirinu. Esto es ,pa' que haga salir buena música, pa' que los instrumentos suenen bien“ ( $\mathrm{BC} 1)$. A este espíritu se le atribuye un poder mágico, es „brujo“: Un hombre está „toca'o por el Sirinu“, cuando aprende a dominar un instrumento musical.

El Supaya o Supay es un espíritu maligno, lo mismo que el Sajara o Sajjra. Los aymaras les temen, pues ,hacen daño al hombre", roban animales y enferman a las personas. En algunos casos se le identifica con un remolino de viento. El Tio es el espíritu que habita en los cerros donde hay minas. Es „demonio“" porque cuando se enoja ,hace derrumbes“, "mata gente“ y „enferma el gana'o“ (SG3).

El Amaru o asiru es una serpiente subterránæa que habita en lugares humedos, en el agua. Ella es responsable de la distribución de las aguas, por eso se le hacen wilanchas en el tiempo de la limpieza de canales (Agosto) y en Carnaval (Febrero). En Caquena al iniciar una wilancha ${ }^{8}$ se le invoca como ,,asiru-amaru !, así como tú me das, yo también te doy! ‘ (BC2). En Putre, algunos informantes le atribuyen un carácter diabólico al asiru: ,sapos (j'ampatu) y culebras (asiru) son amigos del supaya“ (TP2).

Los Condenados, finalmente, son las almas de los difuntos que ,en vida fueron muy pecadores“, los que no han ido al cielo, según la creencia, sino al infierno. Ellos se presentan en lugares oscuros y desolados, también cerca de los cementerios, son peligrosos porque ,tratan de robarle el alma a los vivos" (SG4).

\section{El. TAYPIPACHA.}

El Taypipacha es el lugar donde vive el hombre, es el „,mundo de acá“. Esta zona intermedia se diferencia de las otras dos por la cercanía al hombre y porque en ella se encuentran seres como la Pachamama (divinidad de la tierra) y el Mallku (espíritu de los cerros). Este es un espacio donde se encuentran las fuerzas sobrenaturales asociadas tanto al Arajpacha como al Manqhapacha. Otras expresiones con las cuales los informantes tradujieron es vocablo son :"nosotros" (BC3), ,la comunidad" (CC1), ,el pueblo"(JG1).

Se trata entonces del espacio habitado por el hombre, es el espacio socializado. donde están la casa, el corral, la chacra y el campo abierto; los animales salvajes (vicuña,

\footnotetext{
'Ch'allar es una castellanización del verbo ch'allaña o clí altaña (ch'altar), que se puede traducir como consagrar. Esto consiste en asperciones y livaciones de alcohol sobre cl objeto que se consagra.

"Phawar es también una castellanización del verbo aymara plawaña, que significa ver la suerte con coca o hacer una ofrenda con hojas de coca para conseguir la ayuda de los espiritus.

'Amaru es una expresión quechua que se usa especialmente cn el norle de Chile. Con inás frecuencia se usa la expresión asiru, que identifica una vibora. Grebe, en su trabajo con los aymaras de Isluza, habla de aserro $(1981$, p. 69). Entre los aymaras de Bolivia para serpiente o vibora la expresión es katari.

* Wilancha es el rito donde se sacrifica un llamo blanco macho en honor a la Pachamama y las Achachilas o antepasados, para conseguir su protección o favor y también en agradecimicnto por los bencficios dados.
} 
guanaco, vizcacha, felinos, etc) y domesticados (Ilama, alpaca, cordero); las aves, reptiles y batracios. En esta zona hay lugares sagrados y temibles relacionados con la crianza: Volcanes, cerros y montículos (mallku, markaqullu, samiri), vertientes (jalsuri) y agujeros secos (juturi). Este es el espacio conocido.

Los rasgos geográficos, los animales, las aves y los reptiles se ordenan y clasificados según su dueño y su benevolencia para con el hombre: „,si son de dios o no!“(BC4). Esta expresión refleja un principio de categorización del Taypipacha: Hay lugares malignos y otros sagrados; hay animales de Dios, otros no. Los ,,domesticados“" se diferencian de los „salvajes“ porque los primeros son prestados por la Pachamama al hombre; y los segundos son del Mallku.

Los aymaras trata bien los animales domésticos y cuidan los terrenos de cultivo, porque ellos ,son prestados por la Pachamama“ o ,señora de la tierra“, divinidad dueña de las tierras de cultivo y de los pastos para el ganado. Ella hace crecer la siembra, protege el ganado y las chacras, hace que éstos produzcan, es fecunda. Pero, también puede ser dura con el hombre, puede castigar y hacer daño, por eso es objeto de mucho respeto y veneración.

Entre los aymaras más apegados a "la costumbre" no hay actividad productiva individual o comunitaria que no comience invocando a la Pachamama u ofreciendo un trago en honor a ella, pues el vínculo que los une es la ayuda recíproca. Esta presta al aymara los animales y le ofrece los frutos de la tierra, y por esto en agradecimiento el hombre debe ofrecerle sacrificios y ofrendas, pues son „alimentos“ para ella. Entre los aymaras evangélicos esto no se practica.

Los animales que ,no son prestados al hombre“, como el titi el (felino). el larilari (zorro), el kuntur (condor), el ch'ullumpi (pájaro), el kirkinchu (armadillo), el j’ampatu (batracio) y asiru (serpiente), son respetados y también temidos porque se les asocia con actividades del hombre. El condor representa al Mallku, el quirquincho se relacionan con la buena suerte y el comercio, el asiru-amaru con los canales y el j'ampatu con la Iluvia. Ambos tienen relación con el agua. El titi y el ch'ullumpi están vinculados con la ganadería. El lari-lari es considerado un ser maligno y se le otorga cierta influencia en la agricultura.

En síntesis, en la cosmovisión aymara tradicional los animales y aves poseen atributos míticos y son objeto de veneración por el aymara, pues se cree que pueden afectar el ganado, producir escasez de agua, dañar las siembras, etc. Si los animales son buenos para el hombre, entonces son ,,animalitos de Dios"; si hacen daño al hombre, son entonces „animalitos del diablo“(CHB1).

\section{El ESPACio SAgRado de la COMUNidAD.}

El aymara concibe el ambiente que le rodea, que Ilaman Taypipacha, como sagrado. El territorio de la comunidad y el pueblo o marka constituyen un espacio sagrado, distinto de los sectores más alejados, extracomunitarios y salvajes. El primero es el espacio integrado a la vida y actividades de la comunidad.

En el Taypipacha hay diversos lugares que tienen un carácter sagrado y son objeto de veneración. Estos lugares nacen, por un lado, de la tradición de origen cristiano-católica; y por el otro, de la tradición aymara. Desde este punto de vista, el espacio donde se realiza 
el rito aymara es un espacio sincrético, ya que está organizado según la matriz cristiana, siguiendo los principios españoles: la iglesia, su torre y la cruz central, rodeadas por un muro que delimita el patio -atrio- de la iglesia; los altares o cuatro „esquinas“ del pueblo; más afuera, en los cerros inmediatos a las localidades y que rodean al pueblo, los calvarios; finalmente, el cementerio, de planta rectangular y separado por un alto muro, inserto en el espacio que crean los calvarios.

La matriz aymara sigue principios similares en las localidades estudiadas. No parece importar tanto la distribución u orientación de lugares religiosos ,fuertes“. En cada localidad se puede observar, sin embargo. la existencia de lugares de la misma naturaleza. El patio, corral o chacra, que constituye el centro de la actividad económica, los cerros aledaños o Samiris. Luego, más alejados, donde nacen las vertientes o ríos y canales se encuentra el jalsuri y juturi, lugares que tienen directa relación con los disponibilidad de aguas en la comunidad. Finalmente, más distantes pero aún a la vista, se encuentran las grandes montañas o Mallkus -donde están las achachilas y el tío- y las apachitas montículos de piedras hechos por los aymaras que identifican lugares de paso (sirven de orientación en la puna) y marcan los límites entre comunidades. Mallkus, apachitas, jalsuris y juturis señalan los límites del espacio social. Todos estos puntos están en directa relación con las zonas y/o espacios económicos de las comunidades.

El análisis del espacio religioso muestra una clara yuctaposición de elementos de dos tradiciones religiosas, las que después de siglos conforman una realidad integrada, pero diferenciada y categorizada según criterios bastante claros.

La categorización del espacio y el ordenamiento en categorías duales y complementarias refleja la conceptualización del mundo. El dualismo es un principio ordenador del cosmo y las relaciones entre las partes. El dualismo es una fuente de simbolización en el que el mecanismo básico de aplicación es la metáfora, lo que Ortner llama ,root metaphors“ (1973, p.1340). Así surgen, entonces, las parejas iglesia y torre, Mallku y t'alla (volcanes Parinacota y Pomerape, etc), Mallku y Pachamama, sol y luna, dios y virgen, etc. En otras palabras, la experiencia del núcleo familiar, la relación ,hombremujer" se utiliza para conceptualizar otros aspectos de la realidad (modelo sociológico). La dualidad es, entonces, un principio que permite un ordenamiento conceptual de la experiencia del aymara ante lo social (comunidad), el medio ambiente y lo sobrenatural. En estos tres ámbitos, la dualidad es sinónimo de fecundidad y complementariedad, como lo femenino y lo masculino.

Este principio no contiene un juicio de valor en términos „maniqueistas“. Cuando se da, se debe a la influencia de la tradición cristiana occidental, que ha sido más fuerte especialmente con la llegada de las iglesias evangélicas y fundamentalistas. De ahí que la actitud frente a las divinidades difiere según el apego a una visión de mundo más tradicional, más occidental o más ortodoxa.

En definitiva, el reconocimiento de un poder sobrenatural que controla el medio en el cual se desenvuelve la vida Ileva al aymara necesariamente al acto ritual -como medio de acceder a esta fuente de poder. Puesto que la necesidad y el beneficio disuelven toda forma de juicio moral sobre las divinidades, es precisamente la conducta del aymara (fundada en una ética particular) la que justifica el favor de las divinidades y el beneficio para la comunidad. 
Entre los aymaras, la creencia y el culto relacionan al individuo con la comunidad y la naturaleza. La institución religiosa tradicional posee una organización social que es resultado de la evangelización desde el siglo XVI y de cambios sociales a partir de entonces. En las actuales formas de culto y organización de la autoridad es posible identificar dos orígenes distintos. Por un lado, existe una jerarquía de cargos relacionados con el culto a las imágenes de origen cristiano (santos y virgenes) y, al mismo tiempo, hay líderes religiosos (yatiri) que tienen por misión el culto a las divinidades de origen andino.

Antiguamente, hasta antes de la llegada de los evangélicos a la región, existía en cada comunidad un culto comunal tradicional, que integraba especialistas de medio tiempo dedicados a la veneración de los espíritus y seres tutelares. Había también un culto individual, donde la práctica religiosa no exigía la presencia de especialistas, cuando se trataba, por ejemplo, de ofrendas y sacrificios a los Samiris.

En cuanto al culto de las divinidades de origen cristiano, desde hace algunas décadas el sistema de cargos está sufriendo modificaciones (,desmantelación“) debido a la secularización y la influencia de las sectas evangélicas. Este se compone tradicionalmente de cuatro cargos: El fabriquero (administración), el mayordomo (celebración religiosa), el alférez (festividad, aspecto social), y el preste (oración). Estos cargos envuelven de prestigio a quienes los asumen.

En toda comunidad debía haber un Fabriquero. Sus tareas son la mantención del templo, la administración de los recursos (dinero y tierras de la Iglesia) y la supervisión de las actividades del Mayordomo. Este cargo era en el pasado más importante que la mayordomía. Su autoridad nacía de su función eclesiástica, lo que se simbolizaba por la posesión de las llaves de las puertas del templo. En el transcurso de este siglo éste ha ido perdiendo importancia, en parte, a causa de la chilenización y la secularización. En Caquena hubo fabriquero hasta mediados de la década del 70. En Guallatire, Belén y Putre ya no existen.

EI Mayordomo es el encargado de la devoción a un santo o virgen. Este cargo se asume por tres años, renovables tantas veces como el aymara y la comunidad estén de acuerdo. Sin embargo, se acostumbra dejar el cargo después de este período para pasar a asumir otras mayordomías (otras imágenes) o para dar oportunidad también a otros miembros de la comunidad. Al término de estos tres años se hace un inventario de las cosas que pertenecen al santo o virgen y se anotan los cambios ocurridos (aumentos o pérdidas) ${ }^{9}$.

El número de mayordomos varía de una localidad a otra. En Guallatire, por ejemplo, hay sólo un mayordomo (de la Virgen de la Concepción), lo que se explica por el abandono de la costumbre a causa de las iglesias evangélico-pentecostales. En Caquena existen cinco mayordomias: Para la Virgen Santa Rosa, para San Santiago, para el Santísimo, para el Niño Dios y para las Animas. En Putre existe la mayordomía de la Virgen Asunta y San lldefonso (un cargo), del Santísimo, de las Cruces, del Crucificado, del Niño Dios, de la Virgen del Carmen, de San Juan, de las Cruces Chicas y de las Animas. En Belén hay un „Mayordomo Grande“ o del Señor (Santísimo), de la Virgen María, de la Candelaria, del Carmen, de San Santiago, del Niño Dios y de Animas.

\footnotetext{
"Los Libros de Inventarios de cada Capilla han resultado set una valiosa fuente de infonnación para el siglo XVIII y XIX. Lanentablemente, la mayoría de ellos desapareció con la ocupación chilena. El libro de Guallatire, encontrado en I'89, destaca por sus regisıros desde 1789 hasta 1913. A través de éste y otros libros se ha podido reconstituir la secuencia de ,"1 aspasos" de cargos desde esa fecha hasta 1976.
} 
Entre los mayordomos de una comunidad hay siempre uno que destaca: El Mayordomo Principal o Mayordomo Grande ${ }^{10}$. Según la liturgia católica, la mayordomía más importante correspondía al del Santísimo. Pero, en Guallatire hasta 1976 correspondía al de la Virgen, lo mismo que en Caquena. En Putre corresponde a quien asume simultáneamente el cargo de la Virgen y de San Ildefonso. Sólo en Belén recae en el Mayordomo del Santísimo". Así, las mayordomías se organizan en un orden de importancia dando origen a una jerarquía. En el otro extremo, en menor escala de importancia, se encuentra el mayordomo del Niño Dios.

El Alférez es quien asume la responsabilidad de co-organizar y financiar la festividad de un santo o una virgen. El cargo dura sólo los días de la celebración. Dado que el calendario ritual está preestablecido, al término de cada festividad el mayordomo consultará y buscará entre los asistentes al futuro „pasante" de la festividad" del año que viene. La gente joven acostumbre rechazar la nominación, especialmente por el alto costo que esta responsabilidad conlleva. Los más ancianos comentan esto como un signo de falta de fe, o como una señal de la pérdida de la costumbre.

El Preste es un cargo ya casi desconocido y desaparecido en el presente. Hoy carece de un especial reconocimiento social. El aymara que asume como Preste lo hace casi por decisión propia y sin consulta a la comunidać. No obstante, indirectamente, hay una legitimación de su cargo cuando la comunidad recurre a sus servicios. Este tenía por misión realizar las oraciones cristianas en las diversas celebraciones. Para esto acostumbraba a usar un libro de oraciones. En la actualidad, en algunas celebraciones -así se pudo comprobar en Belén, Putre, Caquena y Parinacota- hay aymaras que rezan en voz alta, en un lenguaje que suena similar al latín, pero que en realidad no es nada. Esto es una huella de las tradiciones impuestas ya en el siglo XVII. En los últimos años en la localidad de Caquena se ha desarrollado un nuevo rol, similar al preste, pero vinculado con la celebración de la Fiesta Nacional en Chile. El „cabecilla“ es el encargado de dirigir la festividad u oración en el templo del pueblo en honor a la Virgen del Carmen (Patrona del Ejército Chileno).

En la actualidad sólo dos cargos, de los cuatro descritos, mantienen una importancia decisiva en la práctica religiosa. En toda celebración debe haber un alférez y el mayordomo. El primero, como ya se dijo, financia y ,pasa“ la fiesta. El segundo dirige la celebración. El alférez se subordina al mayordomo. El primero tiene más importancia en el aspecto social de la celebración, mientras que el Mayordomo es responsable de la correcta realización de la celebración.

Los deberes y responsabilidades de cada cargo son pruebas para el individuo. EI sistema de culto católico tiene directa relación con la estructura social de la comunidad. El ayllu-comunidad del siglo XVIII era originalmente igualitario en cuanto a disponibilidad de recursos, pero diferenciada en cuanto a prestigio e importancia de sus miembros. Por esto, un cargo vacante debe ser un desafío para cada aymara. El que asume un cargo inten-

\footnotetext{
"'El vocablo Principal identifica también al líder político de la comunidad. A través de los nombres y cargos que se especifican en diversos documentos se puede comprobar que los cargos políticos estaban asociados con los cargos religiosos. El Principal de una connunidad era también el mayordomo más importante entre todos.

"Los documentos de siglo XVIIl y XIX mencionan en cada localidad, por lo menos, tres mayordomos: del Santísimo, de la Virgen Patrona y del Santo Patrono del pueblo. De estos se consideraba más importante el del Santísimo, asociado a las celebraciones de Corpus Christi y la Eucaristia.

12 „Pasar la fiesta“" es una expresión que se usa para designar las labores del Alferez. Probablemente, viene del castellano „pasear“ Tradicionalmente, el Alférez (español) paseaba el estandarte por las calles del poblado en las celebraciones importantes de la comunidad.
} 
tará desempeñar éste mejor que su antecesor. Esto ocurre especialmente con el cargo de alférez, porque su significación social es mayor que la de los otros cargos. Una festividad será recordada no precisamente por su importancia religiosa, sino más bien por la abundante comida y alcohol, por la forma en que el alférez acogió a sus invitados. Esta competencia puede llegar a casos extremos.

Así, la competencia en este sistema de prestigio se inicia al asumir el Alferazgo de una celebración. Socialmente, se espera que el que asume el cargo sea un hombre „adulto“, lo que en este caso significa que sea casado, status que garantiza la posibilidad de asumir responsabilidades en la comunidad. Luego de pasar dos o tres fiestas, puede optar a la mayordomía de un santo o virgen, de la cual se supone ya ha sido alférez en alguna celebración anterior. Luego, si lo desea, podrá seguir asumiendo nuevos cargos hasta llegar a ser Mayordomo Grande o Principal.

También el sexo es importante en el sistema de cargos. Los hombres asumen los cargos de importancia. Las únicas mujeres que desempeñan cargos en las localidades - estudiadas lo hacen, porque sus maridos han muerto en el período del desempeño de la mayordomía, razón por la cual la mujer continúa hasta el término o hasta que surga un reemplazante (Mayordomo Grande en Belén). A veces se les permite asumir una mayordomía porque la imagen que representan no es de gran importancia, por lo tanto no otorga prestigio social, ni requiere de un esfuerzo económico, ni organización de un culto especial. En la generalidad de los casos, el desempeño de un cargo exige la participación de una pareja -dualidad y complementariedad-, la mujer debe acompañar al marido. padre o hermano colaborando en las labores domésticas de la celebración (preparación de las comidas, etc.), mientras que el hombre asume las labores del culto.

Paralelo a los cargos anteriores, existen también dos cargos que son de origen andino: El yatiri y el qulliri. Ellos se dedican al culto de los númenes del Arajpacha, Taypipacha y Manqhapacha, los tres espacios de la cosmovisión aymara.

El qulliri es el aymara dedicado a la curación de los enfermos. Generalmente, esta denominación recae en aquellos que por tradición oral poseen un conocimiento profundo de hierbas y otras especies, que les permite aplicar las cualidades de estas como remedios. El rol de ellos es exclusivamente la curación de enfermos. Para el aymara muchas enfermedades, aún cuando puedan tener una explicación fisiológica, se deben a la acción de espíritus. A raíz de esto el Yatiri es más importante que el Qulliri.

El yatiri es un especialista religioso que mantiene un vínculo con los númenes del cosmo. El yatiri es un schamán. Es un hombre que goza de una especial importancia y prestigio por sus cualidades como intermediario o mediador entre los espíritus y el hombre. Por esto goza de gran prestigio y temor. Es el encargado de hacer los sacrificios en tiempos de crisi y ritos calendáricos andinos, sabe leer la suerte de un individuo en la hoja de coca y predecir acontecimientos futuros, puede realizar el rito de la wilancha a los Mallkus y la Pachamama, sabe hacer sacrificios al j'ampatu (sapo) para la lluvia, o al asiru (serpiente) para las aguas en los canales, etc.

El yatiri goza a veces de mayor respeto y temor que el mayordomo. Esto se debe a que los ritos católicos se orientan especialmente a lo comunitario y público (culto comunal) y se dirigen a espíritus reconocidos como „,bondadosos“. La acción del yatiri se restringe, sin embargo, a un culto más privado, casi familiar. Solamente los más ancianos conocen o participan de ritos dirigidos por el yatiri; esto se debe a una cierta disposición de los más adultos a la tradición religiosa autóctona y, por otro lado, a la todavía frecuente 
actitud de secreto e intención de ocultar o divulgar públicamente quién es yatiri. Esto es consecuencia de su persecución en el pasado.

En los últimos años el número de yatiris en la región ha disminuido bastante. Hoy deben ser contratados desde Bolivia. Por cada servicio cobran sumas de dinero que para los mismos aymaras parecen exageradas, aún a pesar de la importancia religiosa de éstos. En el pasado, probablemente, cada comunidad disponía de un yatiri para el rito andino; hoy este lider religioso ha desaparecido completamente de Guallatire, Caquena, Putre y Belén. Esto ha tenido como efecto que la importancia del yatiri también ha disminuido. Ello queda demostrado por la poca recurrencia de los aymaras a los serviciós de este líder religioso. En la actualidad, el rito de la wilancha, los ritos a la lluvia, a los Jalsuris, etc. son realizados por los aymaras sin ser especialistas. Inevitablemente esto conduce a la pérdida del conocimiento religioso, a la improvización y, finalmente, a la secularización.

En resumen, en términos sociológicos, la organización religiosa tradicional se compone de tres tipos de culto. Un culto individual, donde el aymara -sin ser especialistarealiza y participa en ritos andinos o católicos. Este tipo de culto ha adquirido mayor importancia debido a la crisis que enfrenta el culto schamánico. Este consiste en la creencia en que una persona -reconocida socialmente por sus capacidades y dones espiritualespuede intervenir en el mundo sobrenatural de la comunidad (un especialista que dedica parte de su tiempo a predecir el futuro, leer la coca, hablar con los espíritus que pueden dañar y beneficiar al hombre). Por último, un culto comunal, fundado en un sistema de cargos, que especifica los deberes y responsabilidades de los participantes en la celebraciones. Los miembros de esta organización religiosa son especialistas de medio tiempo (preste, alférez, mayordomo, fabriquero).

\section{Ritos Y CALENDARIO DE CELEBRACIONES}

La expresión conductual de la religión es el rito. En su intento por acceder a los beneficios y protección de los espíritus del Arajpacha, Taypipacha y Manqhapacha, el aymara practica ritos y celebraciones para el éxito de las labores de subsistencia y relacionarse con el mundo sobrenatural. La ejecución precisa y correcta de estas prácticas, según lo establece la costumbre, es fundamental para la efectividad del rito. La ejecución de un rito no es objeto de improvisación. La importancia de este acto religioso radica en su vinculación con el pasado. Esta orientación hacia el pasado, que sustentan los ritos, es parte integral del ethos aymara.

El rito aymara es un conjunto de conductas estereotipadas, repetitivas e instrumentales, orientadas según nociones articuladas por símbolos característicos de la cosmovisión aymara, que generan una experiencia con lo sagrado. Cuando el pensamiento religioso reemplaza el sentido común, el aymara genera con el rito un momento solemne. Esta experiencia está enraizada en un sistema de creencias colectivas. Los símbolos que sustentan esas imágenes son arquetipos o estructuras simbólicas socializadas a través del aprendizaje de los mitos.

En el rito no sólo es importante la conducta o práctica religiosa, sino que también el equipo material y ambiente físico donde este se efectúa, pues contribuye a reforzar el ambiente religioso e interpelar los sentidos (la percepción), logrando de esta manera la sensibilidad necesaria para experimentar lo sagrado. Los elementos psicotrópicos -beber 
alcohol y pijchar coca ${ }^{13}$ - juegan un rol fundamental. También el baile y la música, la deprivasión sensorial y el ayuno, etc.

El rito aymara también es parte de la tecnología de una comunidad y está iluminado por el principio de la reciprocidad. Los ritos ayudan a la subsistencia. Las celebraciones buscan una siembra y cosecha exitosa o la salud del ganado. Las ofrendas y sacrificios son elementos substanciales de la relación con los seres sobrenaturales. El aymara espera que le retribuyan sus sacrificios con beneficios para su familia y la comunidad.

El calendario ritual lo conforman celebraciones de origen aymara, vinculadas a las actividades agropecuarias, y celebraciones de origen español, relacionadas con las celebraciones sociales y religiosas. En las localidades estudiadas se realizan tres tipos de rito: (a) calendáricos, (b) de transición y (c) de crisis. Los ritos de transición están orientados al individuo y se realizan una sola vez en la vida de la persona (bautismo, corte de pelo, matrimonio y muerte). Estas celebraciones se dirigen a la iniciación y cambio de estado (rol y status) del aymara en la comunidad. Dado que la escuela conduce a una 'socialización distinta y la emigración a la ciudad genera un ausentismo en las actividades de la comunidad, la mayoría de los ritos de transición, especialmente los que tienen relación con la iniciación de los jóvenes, están en crisis.

Algo similar sucede con los ritos calendáricos. Estas son celebraciones recurrentes en las que interviene toda la comunidad. Están relacionadas con el ciclo económico y vida social, de tal manera que se realizan con mayor frecuencia que otros ritos, como por ejemplo los ritos de crisis, que no obedecen a un ciclo o secuencia, pero que pueden realizarse en cualquier momento. En ellos pueden participar ya sea un individuo o la comunidad entera. Estos buscan la solución de problemas urgentes e inesperados; por eso se hacen en situaciones de incertidumbre y ansiedad (sahumerio, ofrendas, wilanchas, etc). Los ritos calendáricos tienen la particularidad de efectuarse como parte de un secuencia anual. Detrás de ellos hay implícita una concepción cíclica del tiempo.

Para elegir el momento en el que se deben efectuar dichos ritos y celebraciones se toma en consideración tanto indicadores astronómicos y climáticos -especialmente en el caso de los ritos agropecuarios-, como también el calendario litúrgico y santoral católico cuando se trata de las celebraciones religiosas de la comunidad.

Los ritos y celebraciones se diferencian, además, según su finalidad. Ellos se dirigen al éxito de una actividad económica o la renovación de vínculos sociales, pero ambas categorias son arbitrarias, ya que en el examen de cualquier rito calendárico siempre se encontrarán propósitos religiosos, sociales y económicos. No obstante, aquí seguiremos esta clasificación sólo para fines del análisis.

\section{El CICLO RITUAL EN LA VIDA RELIGIOSA Y SOCJAL DE LA COMUNIDAD.}

En las cuatro localidades estudiadas se celebran o celebraban los siguientes acontecimientos: Carnaval, Semana Santa, Fiesta de la Cruz, Corpus Christi, Todas las Almas y Santos y Fiesta Patronal. En la actualidad, en Guallatire y Putre, por ejemplo, estas festividades no encuentran la acogída que tenían antes. Esto se debe a la conversión a las iglesias evangélicas y la secularización de los aymaras migrados a la ciudad.

\footnotetext{
${ }^{12}$ Pijchar coca: es una castellanización del verbo aymara pijclsana, que identifica el acto de mascar coca en los ritos.
} 
Todas estas festividades son de origen español y fueron impuestas ya en el siglo XVI por el Gerónimo de Loayza (Obispo de Lima). Los días de fiesta entre los indios debían ser todos los domingos, Navidad, Circunscisión, Epifanía, Resurrección, Ascención, Pascua del Espíritu Santo (Pentecostes), el día de Corpus Christi, la Natividad de la Virgen, Anunciación, Purificación, Asunción y la Celebración de San Pedro y San Pablo.

Estas celebraciones prescriben un ciclo vital (vida y muerte de Jesucristo) para la vida religiosa de la comunidad siguiendo un modelo definido en la liturgia romana, centrada en la historia de la salvación. El aymara no comprendió esto en el pasado y no lo comprende aún hoy. La experiencia católica del aymara no es cristocéntrica. Cristo juega un rol muy segundario en la cosmovisión aymara. El no es la figura central de la celebración de la comunidad. Para el aymara es más importante el Santo o Patrono, el intermediario.

Las festividades más celebradas en el altiplano y en la cordillera son: Carnaval, la Fiesta de la Cruz, Fiesta Patronal y Todos los Santos y Difuntos. Las restantes festividades se celebran sólo cuando hay un sacerdote.

Carnaval o anat se celebra 7 semanas antes de la Semana Santa. Los aymaras personifican el Carnaval en un muñeco, „Juan Domingo Carnavalón“, el que queman o entierran al final de las festividades o el miercoles siguiente (,Miercoles de Ceniza“), para reaparecer el año siguiente.

Los aymaras tomaron esta celebración de los españoles, pero no sin reformulaciones. Por ejemplo, al ,jueves de compadres", día en el que, según la costumbre española, se renuevan los vínculos sociales, los aymaras de Arica agregaron otro significado: Los Mallkus. Así, los „compadres“ son los Mallkus. Lo mismo ocurrió en Isluga (Martínez, 1976, p. 285). Hoy la celebración integra ritos de precosecha y se le relaciona con la fertilidad de la tierra. De esta forma, la Pachamama reemplazó la tradición y mitología cristiana europea.

La Fiesta Patronal es una festividad de origen español que se celebra siguiendo el Santoral de la Iglesia Católica. Cada comunidad-pueblo, como también algunos caserios, tiene nombre de santo o virgen que son reconocidos como los „Patrones“. Son espíritus tutelares que protegen a las familias de la localidad. Inicialmente los nombres de las localidades fueron asignados según el día en que se hizo la primera misa en el lugar. Luego los eligió el obispo de Arequipa (como sucedió en Caquena).

La fiesta patronal de Belén se celebra el 25 de Julio (San Santiago), en Putre el 15 de Agosto (Fiesta de la Asunta) y en Caquena se celebra el 30 del mismo mes (festividad . de Santa Rosa de Lima). En Guallatire la fiesta se celebra el 22 de Septiembre, el día de La Inmaculada Concepción).

En algunos casos la Fiesta Patronal ha sido tan importante que las demás festividades en honor a otros santos y virgenes han sido trasladadas a esos días, cuando se reune la mayoría de los comuneros. Esto se debe a que, por razones del ciclo económico, en las localidades altiplánicas algunas festividades encuentran a la gente dispersa en los campos. La gente procura cumplir entonces todos sus deberes religiosos de una vez.

La celebración ha sufrido, sin embargo, cambios importantes que se explican por el ausentismo de los comuneros y la crítica de los aymaras evangélicos. Así, por ejemplo, en Guallatire probablemente esta festividad no se celebrará más, puesto que la gran mayoría de la población ha ingresado a la Iglesias Pentecostal y del Nazareno y se declara en contra de la ,idolatría“.

Todos los Santos y Difuntos se celebra el 1 y 2 de Noviembre. En esos días se 
hacen ritos en recuerdo a las almanaka (las almas de los difuntos en los últimos tres años), a las nayra almanaka (almas viejas) y a las achachilas (antepasados de la comunidad). La mayoría de los aymaras participan en estas celebraciones. El aymara tiene la convicción de que el alma viene a casa para visitar a sus familiares. Por esta razón, el aymara „atiende“ a los parientes muertos preparándoles alimentos y otras especies que les gustaban, ya que estos puede interceder ante las divinidades, para el bien de la familia y la comunidad. Por esto el rito consiste en recibir al difunto como un pariente vivo. Los muertos son recordados al phichjar la coca ${ }^{14}$. El objetivo de esta celebración es revitalizar el lazo social que une a vivos y muertos.

\section{El CICLO RITUAL EN LAS ACTIVIDADES ECONÓMICAS DE LA COMUNIDAD.}

La siembra, la cosecha y el pastoreo (ciclo económico) enmarcan una secuencia de celebraciones (ciclo ritual) que se realizan según el ciclo climático en la región (ver Esquema). El principio generador de estos ritos es el intento por controlar la naturaleza a través de la intervención de los diferentes númenes, especialmente de la Pachamama.

En Arica los aymaras identifican 3 períodos climáticos importantes: Un tiempo de lluvias (jallu pacha), un tiempo de heladas (juypi pacha) y un tiempo seco (awti pacha). Cada una de estas „estaciones“ está caracterizada por labores y actividades económicas bien diferentes. Con pequeñas variaciones en la duración de estos períodos, lo que puede deberse fácilmente a variaciones climáticas entre ambas zonas, el ciclo económico de los aymaras no difiere fundamentalmente entre Arica y Tarapacá's.

Las características geográficas de Tarapacá (distribución de las cuencas hidrográficas de los ríos Isluga, Camiña, etc en dirección Este-Oeste) permiten un acceso directo y estacional a sectores altos y bajos distantes de la localidad, esto facilita el desarrollo de actividades agropecuarias donde hay un uso más extensivo de los recursos. En la zona de Arica, sin embargo, las hoyas hidrográficas de Cosapilla y Lauca, orientadas en un eje aproximado Norte-Sur, están separadas del sector cordillerano más bajo por una alta cadena de montañas (Taapaca-Chapiquiña), que obliga a las comunidades a desarrollar actividades económicas diferentes e independientes: En el sector cordillerano la agricultura y en el sector altiplánico la ganadería.

El jallu pacha (tiempo de lluvias) es el tiempo de la trasquila y nacimiento de ganado auquénido. En el caso de los pastores el principal rito es el „floreo al ganado" o $\mathbf{k}^{\prime}$ illpa ${ }^{16}$, que en el altiplano ariqueño se realiza en Febrero, cuando disminuyen las lluvias. Este rito tiene como finalidad la fecundidad del ganado.

En el caso del ganado ovino, el „floreo al cordero" se realiza en juypi pacha (tiempo de heladas), el día de San Juan (24 de Junio). En esta celebración los aymaras dan gracias al Santo y le piden protección y salud para el ganado. Este tiempo es decisivo para la sobrevivencia de las nuevas crías que nacieron en el jallu pacha.

Entre los agricultores las festividades importantes se celebran según el tiempo de siembra y cosecha. Ambas actividades conforman las etapas principales del ciclo agrícola.

\footnotetext{
${ }^{14}$ Plichja: quema, phichjaña: quemar. El acto de quemar coca se asocia a ias almas. En este rito, la vela es el alına a quien se le regalan hojas de coca para masticar (pijchaña).

${ }^{15}$ Estos periodos reciben en el sector de Cariquima (Tarapacá) otros nombres: jhallu pacha, tha pacha y yupu sat(a), respectivamente (Olmos \& Pérez, s/f, p. 16).

${ }^{16} \mathrm{~K}$ 'illpa es el adomo de lana con vivos colores que se pone en las orejas del animal. El verbo killpaña identifica el rito de "Inarcar".
} 
El motivo central de las festividades es la fertilidad de la tierra. En la primera etapa el Pachallampe marca el tiempo de preparación de la tierra y la siembra (Septiembre, Octubre y parte de Noviembre). En la segunda etapa, entre Marzo, Abril y parte de Mayo, la Fiesta de la Cruz señala el término de la cosecha.

El ciclo agrícola es el siguiente: Al finalizar el juypi pacha se inicia la rotulación de las chacras, se limpian los canales que permitirán el riego y abastecimiento de agua para la chacra y la localidad. La divinidad principal a la cual se orientan los ritos relacionados con las aguas es el Amaru o Asiru. Luego, en awti pacha (tiempo seco) se realiza el Pachallampe, celebración de la siembra de la papa, donde la divinidad central es la Pachamama y el Mamajatha (espíritu de la papa). En jallu pacha, durante la celebración del Carnaval (Febrero) se realizan ritos de precosecha, lo cual también se efectúa en relación con la celebración de la Virgen de la Candelaria. El ciclo agrícola finaliza con la cosecha entre los meses de Marzo y Mayo, según se trata de maíz o papas. Ciertamente se cultivan otros vegetales -como orégano y ajo- pero los ritos están relacionados fundamentalmente con la siembra y cosecha de los cultivos tradicionales y prehispánicos. No obstante, cuando el aymara agradece por la cosecha, piensa en todos los productos que recibe la familia.

Entonces, antes de comenzar el juypi pacha, se realiza la fiesta a los Mallkus y Samiris en agradecimiento por la cosecha. Esta es la fiesta de la Cruz.

La Fiesta de la Cruz se celebra el 3 de Mayo. En esos dias los aymaras hacen ritos de agradecimiento a los Mallku-cruces que rodean las chacras y pueblos. La cruz es para ellos un símbolo protector: Ella permite una buena cosecha. La festividad está compuesta de tres etapas: 1) la bajada desde el cerro, 2) el velorio en la casa del alférez y 3) la subida al cerro.

La celebración comienza una semana antes, cuando las personas van a buscar las cruces ,protectoras“ del pueblo, que durante el año permanecieron en las cumbres de los cerros más altos (samiris). Ese día llevan comidas y bebidas. Al llegar a la cumbre preparan una guatia (comida típica de la región). Cambian los adornos de la cruz y le ponen nuevas „vestimentas", las que han preparado semanas antes (flores de papel, telas bordadas). Después las llevan a la iglesia. Allí las dejan una semana. Cada familia se encarga de una cruz. La noche del día 2 de Mayo se hace el velorio. La gente se reune en la casa del Mayordomo de la Cruz, cruz principal que se encuentra sobre el Markaqullu. Encienden y depositan una gran cantidad de velas en los alrededores del altar-cruz y rezan el Rosario. Al día siguiente van al templo y las bendicen. Luego cargan la Cruz y la llevan al cerro correspondiente. (subida). Al llegar a la cumbre, se arrodillan frente a la Cruz; es el momento de hacer el pagu o pago ${ }^{17}$. Los participantes ch'altan, phawan y después comen. En gratitud por el acompañamiento, el mayordomo ofrece en el lugar una guatia a los presentes, luego regresan al pueblo y se reunen nuevamente en casa del mayordomo, donde continuan bailando y bebiendo.

En esta celebración los aymaras han hecho una síntesis de dos símbolos religiosos importantes: La Cruz, impuesta para la veneración ya desde los primeros años del contacto, y la huaca indigena (el Mallku y el Samiri). La muerte de Cristo en la Cruz es para e] cristiano símbolo de vida. Para el aymara los cerros protegen las familias y desde sus faldas Mama t'alla les concede buenos terrenos para sembrar: Ella es fuente de vida que permite

\footnotetext{
"Pagu: ténnino que identifica la ofrenda o sacrificio del aymara a la divinidad como retriburión a la ayuda recibida. Un ejemplo de „pago de la manda“ consiste en ponerse de rodillas y dar tres vueltas alrededor de la base de la Cruz (estas vueltas deben hacerse de izquierda a derecha).
} 
crecer y multiplicar las cosechas. Ambos elementos tienen como denominador común el que son „fuente de vida“, son signos de fecundidad.

\section{EL SINCRETISMO EN LA COSTUMBRE DEL AYMARA ARIQUEÑO.}

Afirmar que la religión de los aymaras es resultado de un sincretismo no es una novedad. Bollaert (1860, en Larrain, 1975, p. 474) y Forbes (1870, p. 230) lo habían observado en la segunda mitad del siglo pasado. La mezcla de elementos católicos y aymaras que se observa en las celebraciones religiosas de las poblaciones de la región ariqueña se explican por el contacto y rol que desempeñó la Iglesia Católica entre los siglos XVI y XIX.

Si bien durante los siglos XVII y XVIII las idolatrías ponen en evidencia la coexistencia de dos formas religiosas que competían, con el paso del tiempo el aymara asumió obligadamente elementos del ritual católico. Esto no podía ser de otra manera. La temprana reelaboración de los contenidos religiosos explica el carácter sincrético de las celebraciones entre los aymaras deI siglo XX. La comparación de la religiosidad española de los siglos XVI-XVII con las festividades de los aymaras de hoy justifica esta afirmación y permite ejemplificar los cambios y transformaciones.

El concepto sincretismo expresa las transformaciones que experimenta el sistema religioso e identifica el proceso de cambio que resulta de la confrontación de dos religiones. Aquí conviene tener presente la conceptualización propuesta por Berner (1979, p. $68-85 ;$ y 1982). Según este autor, cuando dos sistemas entran en contacto y compiten por la hegemonía religiosa se desencadena un proceso de sistematización: Los individuos registran el nuevo discurso religioso y lo revisan, contrastándolo, reelaborando, adaptando y seleccionando los elementos que les resultan importantes desde su perspectiva religiosa. Este concepto, sistematización, integra todos los intentos de los seguidores de una religión por solucionar los conflictos que surgen de la competencia entre las religiones en contacto $(1979$, p. 71). Este encuentro de religiones puede afectar a la religión como sistema total o parte de ella. Esta conceptualización es valiosa, pues considera la posibilidad -hasta cierto punto lógica- de que en el sincretismo se desarrolle un proceso de sistematización a nivel de elementos, pero no necesariamente una sistematización a nivel de sistema.

En el plano de los elementos que componen los sistemas religiosos, el sincretismo asume diversas modalidades. Primero, en el transcurso de los siglos ha ocurrido un proceso de absorción religiosa, esto es: Un elemento ha asumido la función de otro $\mathrm{y}$, al mismo tiempo, lo ha suprimido o relegado de tal manera que la combinación entre ambos es reconocible sólo a través de un análisis secundario o más profundo. Por ejemplo, entre los aymaras de Putre la Cruz, depositaria de las rogativas, ofrendas y agradecimientos por la cosecha en la Celebración de las Cruces, asume la función del Mallku (cerro protector y dueño de una comunidad), restándole aparentemente importancia y desplazando a los Samiris (cerros protectores particulares).

Por otra parte, también tiene lugar un proceso de adopción religiosa. Esto ocurre cuando los límites -y con esto Ia competencia entre diferentes elementos- son superados sin que alguno de los elementos llegue a ser absorbido por el otro, surgiendo así una combinación a partir de elementos ya antes existentes y siendo aún reconocible para un miembro del sistema respectivo. Ejemplo de ello es que algunos elementos de la tradición religiosa hispana han sido adoptados en la celebración aymara de la siembra (Pachallampe). Estos, que originalmente competian o eran concurrentes (San Santiago, Pachamama, 
Mamajatha), están hoy presentes y vinculados constituyendo una unidad inseparable, pero diferenciable.

En el contexto de un proceso de acumulación religiosa entre los aymaras, esto es: Cuando un elemento es recubierto de otros significados, es posible reconocer los siguientes mecanismos:

a) Una identificación, que ocurre cuando elementos diferentes son explicitamente reconocibles como similares o cuando son intercambiables. Esto ocurre entre el sol (inti) y el Dios cristiano; entre la luna (phaxsi) y la Virgen Concepción. También entre San Santiago y el rayo (illapu).

b) Una transformación, que sucede cuando, como consecuencia de una reinterpretación consciente, un elemento experimenta un cambio de significado. Esto ocurre en el caso del Supay y el demonio. Aquí, como consecuencia de la reinterpretación del significado por obra de los misioneros católicos, como habría sido el caso del Supaya, éste asume el carácter de demonio, similar al diablo de la religión católica.

c) Un cambio de función, que ocurre cuando un elemento de un sistema es integrado como elemento del otro sistema sin que ocurra un reinterpretación consciente. Este es el caso de San Isidro. En la localidad de Guallatire, por ejemplo, para uno de los informantes el santo ,es el santo de los escolares“, pues tiene un libro en su mano derecha. Un ejemplo más general es el de San Juan, Patrono de los Corderos.

d) Una substitución de elementos, que sucede especialmente en lo que se refiere a la organización del culto comunal. Aquí un elemento ha sido reemplazado a tal punto que al mismo tiempo hay un proceso de distanciamiento y diferenciación de su fuente (anatematizar), mientras su función es adoptada por un elemento nuevo o especialmente configurado para ese propósito, pero proveniente del sistema concurrente. La introducción de un sistema de Cofradías en un tiempo de conflicto entre ambos sistemas conduce a largo plazo a una substitución de la estructura del culto comunal aymara prehispánico. El sistema de cargos vinculados con la organización cofradial reemplaza o resta importancia del sistema de autoridad religiosa aymara prehispánica.

e) Una igualación, que sucede cuando en un sistema surge un elemento, que equivale a otro del sistema concurrente. Esto ocurre en la integración de la Pachamama, el Mallku y el Markaqullu en la Fiesta Patronal y otras festividades católicas. Así actualmente en la Fiesta Patronal hay elementos andinos que equivalen en importancia a los Santos Patrones del pueblo.

f) Finalmente, también se puede identificar un proceso de asociación, que ocurre cuando se entablecen relaciones entre diferentes elementos sin suprimir los límites entre ellos, de tal manera que éstos son reconocibles aún para los seguidores del sistema respectivo. Aquí no se compromete la identidad de los elementos. Entre los aymaras se han aplicado diversos modelos. En el caso de la iglesia-templo (llamada también t'alla-iglesia), „el“ torre (Mallku-torre) y de la cruz central (taypi) se proyecta un modelo sociológico en el cual se identifica a las diferentes partes como miembros de una familia: Mujer, hombre, hijo res- 
pectivamente. Un modelo ontológico, por el contrario, se aplica en el caso de la Virgen y la Pachamama. Ellas son de la misma naturaleza, son idénticos pero diferenciables. Por último, también se puede reconocer un modelo espacial: Un buen ejemplo es San Santiago y su ubicación al occidente de las localidades altiplánicas estudiadas. Otro ejemplo es, según se dice, que en su segunda venida, Jesucristo vendrá por el oriente, desde donde nace el sol.

La religión de los aymaras del siglo XX es diferente de aquella del siglo XVl o XVII. Ella es una totalidad armoniosa que resulta de una sistematización de dos tradiciones religiosas y de la reelaboración de símbolos y elementos dispuestos en una coherencia funcional. El contacto entre la religión aymara y el sistema religioso católico no condujo a una síntesis religiosa. Aquí no hay involucrado un proceso creativo por el cual surgen nuevos elementos. Se trata de un sincretismo a nivel de sistema, donde los límites y el conflicto original entre ambas religiones, luego de más de cuatro siglos de competencia, ha sido ya superado. No hay entre algunos aymaras un intento consciente de separarse o diferenciarse del origen histórico de las actuales manifestaciones religiosas. Lo contrario identificaría un proceso de falso sincretismo o „pseudo-synthese“ (ibid, p.74).

La costumbre está más relacionada a los símbolos y significados de la tradición religiosa aymara que católica. Sin embargo, son los elementos católicos los que han recubierto a los andinos. Detrás de las expresiones católicas hay significados más profundos que obedecen a categorías y principios andinos. La relación actual entre los componentes históricamente diferenciables es por esto armónica. Ambos sistemas funcionan complementándose y justifican su existencia sin que exista una valoración más positiva o negativa de uno de ellos, ya sea en términos evaluativos, epistemológicos, cronológicos, genéticos $\mathrm{e}$ inclusivos.

\section{RELIGIÓN, ETHOS E IDENTIDAD AYMARA.}

El aymara tradicionalista es un hombre creyente (homo religiosus). La religión juega un rol importante e indiscutible en la vida del individuo y la comunidad regida por principios tradicionales. Todas las experiencias y situaciones importantes en la vida tienen un trasfondo religioso, porque el modelo mítico de la cosmovisión dota la realidad de una naturaleza sagrada; así también el espacio físico que rodea al hombre. Este sentido generalizado de lo sagrado se reconoce en las asociaciones y vínculos que establece. Para el aymara, por ejemplo, hay un paralelismo, una relación entre la vida social, la enfermedad, las divinidades y los fenómenos de la naturaleza. Las prácticas religiosas permean las labores cotidianas. Los aymaras de Guallatire, por ejemplo, al levantarse y comenzar el día observan antes si el Mallku (el volcán) aún respira (fumarolas).

Se puede afirmar que la religión de los aymaras es natural. Las especies animales y los rasgos del paisaje que conforman el habitat (volcanes, cerros, vertientes, etc.) están integrados a su concepción sagrada del mundo. El aymara tradicional tiene conciencia de la presencia de lo divino e inmanencia de lo sagrado, conciencia que se expresa en el reconocimiento de un espacio, objetos, seres o entes sagrados que lo rodean en todo momento. Al mismo tiempo, él cree que los seres sagrados están consciente de él, cree que su conducta no pasa desapercibida ante las divinidades. En el mundo sobrenatural aymara la Pachamama y demás divinidades ayudan y/o castigan al hombre según su conducta. 
Esto explica los ritos y celebraciones periódicas y esporádicas en busca del beneficio y la intercesión por la comunidad.

La religión aymara es instrumental, ya que a través del rito el aymara busca ejercer un control sobre el medio y los acontecimientos, evitando el azar, la casualidad y la desgracia. Los ritos persiguen el beneficio para la comunidad. Desde una perspectiva tecnológi$\mathrm{ca}$, los rituales asociados al ciclo económico son un componente fundamental del devenir de la comunidad. El mundo sobrenatural es fundamental para la satisfacción de las necesidades. Por esto, las estrategias de subsistencia gozan de un carácter también simbólico. La tecnología simbólica -orientada por principios religiosos y conocimientos adquiridos en la interacción con el medio- es la base del acto ritual.

La religión aymara es el resultado de un proceso de sistematización de elementos cristianos integrados a una experiencia religiosa andina tradicional (sincretismo). Los ritos y festividades obedecen a factores sociales, históricos y el ciclo económico. Los elementos cristianos han sido reformulados e integrados, otorgándoseles un rol más coincidente con una visión andina que occidental.

En la cosmovisión y ritos se pueden identificar las categorías mentales del aymara tradicional, los elementos se organizan y actúan siguiendo principios básicos. El rito actualiza el ethos. El dualismo, la complementaridad y la reciprocidad son expresados allí simbólicamente.

La dualidad es un principio organizador del cosmo y de las relaciones que lleva a un ordenamiento conceptual de la experiencia. Según esto, hay maneras de proceder más válidas y efectivas. La concepción de una realidad formada por sectores y espíritus diversos y diferentes (dualismo) se disuelve con la complementariedad. Ella integra las partes complementándolas y permite así la fecundidad. En todo rito está implícita esta concepción. El éxito de la siembra, que manifiesta en una abundante cosecha de la papa, se asegura con la participación de la Pachamama, Mamajatha y Mallku-cruces. La fecundidad de la chacra es resultado de la complementación entre el hombre, responsable del Pachallampe (siembra) y la Celebración de la Cruz (cosecha), y las divinidades de los tres niveles que conforman la cosmovisión aymara..

El dualismo y la complementariedad son categorías observables en toda conducta social tradicional, y contribuyen a asegurar la permanencia de la comunidad. La complementariedad y reciprocidad son principios que ordenan la acción social: Modelan la conducta entre los aymaras y a su vez la relación del hombre con las divinidades.

En sintesis, se puede concluir que el aymara es religioso por su experiencia de lo sobrenatural, por la confrontación con el medio natural y la sociedad. Estas son tres fuentes de la religiosidad aymara y constituyen el núcleo de la práctica tradicional, que se funda en una ideología particular con un ethos propio.

El ethos andino, compuestos por categorías, criterios y valores tradicionales, constituye para algunos aymara todavía un modelo coherente y funcional, especialmente para aquellos más apegados a la costumbre. La costumbre expresa el ser aymara. Los individuos mayores se identifican con ellas y se sienten auténticamente aymaras especialmente cuando celebran al Mallku, la Pachamama, o cuando hacen una wilancha. La costumbre es una fuente de símbolos, principios y categorías que sustentan la identidad aymara tradicional. Para otros aymaras, sin embargo, los convertidos a las Iglesias evangélico-pentecostales, las celebraciones tradicionales son idolatría. Ellos no se identifican con estas. 
Las prácticas religiosas tradicionales, en sus diversas expresiones, recrean al ethos aymara. La costumbre conduce a una experiencia particular, reproduce una orientación y actitud básica recreando al mismo tiempo determinados modos de acción. Los contenidos y significados asociados a la Pachamama, por ejemplo, símbolo central de la religiosidad aymara tradicional, interpela al individuo generando y configurando la conducta ritual.

Las divinidades y cosmovisión aymara son importante puesto que a través de ellas los miembros de la comunidad extensiva y sistemáticamente formulan y recrean relaciones, paralelos e imágenes -gracias a los procesos de simbolización y analogía- que integran de una manera coherente los diversos aspectos o ámbitos socioculturales de] sistema tradicional. La importancia de esta figura símbolo en la religiosidad y en el ethos de la comunidad aymara tradicional es indiscutible.

La comunidad tradicional, aquella cuyo sustento ideológico y sus instituciones mantienen aún rasgos particulares andinos, funciona en base a la práctica de la reciprocidad y complementariedad de sus miembros. La religión tradicional no sólo privilegia estas conductas, también las recrea y las justifica. La crisis surge cuando los individuos ya no se dejan llevar en la praxis social por la tradición y la costumbre, cuando instituciones socializantes (como la escuela, la conscripción militar y los medios de comunicación), u otras (como las organizaciones comunales urbanas, y las iglesias evangélicas -sociológicamente sectarias y rupturistas-) introducen formas ajenas y contrarias al estilo de convivencia social andino tradicional. 
Las prácticas religiosas tradicionales, en sus diversas expresiones, recrean al ethos aymara. La costumbre conduce a una experiencia particular, reproduce una orientación y actitud básica recreando al mismo tiempo determinados modos de acción. Los contenidos y significados asociados a la Pachamama, por ejemplo, símbolo central de la religiosidad aymara tradicional, interpela al individuo generando y configurando la conducta ritual.

Las divinidades y cosmovisión aymara son importante puesto que a través de ellas los miembros de la comunidad extensiva y sistemáticamente formulan y recrean relaciones, paralelos e imágenes -gracias a los procesos de simbolización y analogía- que integran de una manera coherente los diversos aspectos o ámbitos socioculturales del sistema tradicional. La importancia de esta figura símbolo en la religiosidad y en el ethos de la comunidad aymara tradicional es indiscutible.

La comunidad tradicional, aquella cuyo sustento ideológico y sus instituciones mantienen aún rasgos particulares andinos, funciona en base a la práctica de la reciprocidad y complementariedad de sus miembros. La religión tradicional no sólo privilegia estas conductas, también las recrea y las justifica. La crisis surge cuando los individuos ya no se dejan llevar en la praxis social por la tradición y la costumbre, cuando instituciones socializantes (como la escuela, la conscripción militar y los medios de comunicación), u otras (como las organizaciones comunales urbanas, y las iglesias evangélicas -sociológicamente sectarias y rupturistas-) introducen formas ajenas y contrarias al estilo de convivencia social andino tradicional. 


\section{BiBLIOGRAFIA}

Albo, Xavier. "La experiencia religiosa aymara". Rostros Indios de Dios. Los amerindios cristianos. Manuel Marzal et al. Edit. Abya-Yala, Quito, 1991. p. 201-265.

Barrientos, Lina. "La Cruz de Mayo: un ritual aymara en el interior de Arica". Revista Musical Chilena. San-

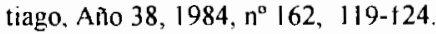

Barriga, Victor. Memorias para la historia de Arequipa. Lima Tomo VI. 1948.

Berg, IIans van den. Diccionario religioso aymara. CETA. Iquitos-Perú, 1985.

Berg, Hans van den. La tierra no da así no más. Los ritos agricolas en la región de los aymaras cristianos. CEDLA-Amsterdam. Nr. 18, 1989a.

Berg, Hans van den. "La celebración de los difuntos entre los campecinos aymaras del altiplano". Anthropos. San Agustín. Nr. 84, 1989b, p. 155-175.

Berner, Utrich. "Der Begriff, ,.Synkretismus" -ein Instrument historischer Erkenntnis?". Saeculum, Freiburg. Vol. 30, 1979, 68-85.

Berner, Uirich. Untersuchung zur Verwendung des Synkretismus-Begriffes. Wiesbaden, 1982.

Bertonio, Ludovico. locabulario de la lengua aymara. Francisco Cato (Ed). La Paz. (1612), 1956.

Bollaert, William. "Observations on the geography of Southern Peru, incluiding Survey of the Province of Tarapaca, and Route to Chile by the coast, of the Desert of Atacama". Journal of the Royal Geographycal Society of London. Vol. 21, 1851, 99-130.

Bollacrt, William. "Observations on the history of the Incas of Peru, on the indians of South Peru, and on some indians remains on the Province of Tarapaca". Journal of the Elhnological Society of London Vol. $3,1854,132-164$

Bouysse-Cassagne, Theresse. "Urco and uma: Aymara Concepts of space". en Anthropological History of Andean Polities. John Murra, N. Wachtel \& J. Revel (Ed), Cambridge, 1986, 201-227.

Briones, Luis el al. La pinfura mural en la Sierra de lquique y el Altiplano de Arica (Primera Región - Chile). Segundo Informe Técnico de Avance Año 1989, Proyecto UTA-OEA. Arica. 1990.

Buechler, Hans. The Masked Media. Aymara Fiestas and Social Interaction in the Bolivian Highlands. New York: Mouton Publishers, 1980.

Cotari, Daniel et al. Diccionario Aymara-Castellano, Castellano-Aymara. Instituto de ldiomas Padres de Maryknoll. Cochabamba. 1978.

Farelly, Brian. "El v. Bernedo y el Rosario como método de Evangelización en Hispanoanérica (Alto-Perú)", Teología Espiritual, Valencia. Vol. 17, $\mathrm{n}^{\circ} 48,1972,401-412$.

Forbes, David. "On the Aymara Indians of Bolivia and Perí". Journal of the Ethnological Society of London. Vol. 2, $1870,193-305$.

Grebe, María Ester. "Cosmovisión Aymara", Revista de Santiago, Santiago. vol. 1, 1981, 61-78.

Grebe, María Ester. "El culto a los animales sagrados emblemáticos en la cultura aymara de Chile". Revista Chilena de Antropologia. Santiago. Vol. 8, 1989-90. 35-5.

Harris, Olivia \& Bouysse-Cassagne, Theresse. "Pacha: en torno al pensamiento aymara", en Raíces de América. El Mundo Aymara. Madrid, 1988, 217-275.

Hidalgo, Jorge \& Diaz, Victor. "Cartas del Obispo de Arequipa sobre los indios del Corregimiento de Arica; 1620-1638". Revista Chungara. Arica. Vol. 15, 1985, 77-97.

Isbell, Billie Jean. "La otra mitad esencial: un estudio de complementariedad sexual andina", Estudios Andinos, Pittsburg, Vol. 5, n I, 1976, 37-56.

Isbell, Billic Jean. "Introduction to Andean Symbolism". Actas del 42. Congreso Internacional de Americanistas, Paris. Tomo 4, 1978, 259-268.

Jorda, Enrique. "Visión aymara del espacio (sincretismo)", Boletín del Institulo de Estudios Aymaras, Chucuito. $n^{\circ} 19,1985,56-74$.

Kessel, Juan van. Holocausto al progreso. Los aymaras de Tarapacá. CEDLA, Amsterdam, 1980.

Kessel, Juan van. "La cosmovisión aymara", en Etnografia. Sociedades indigenas contemporaneas y su ideología. J.Hidaigo et al. (de). Edit. Andrés Bello, Santiago, 1996, 169-187.

Larraín, Horacio. "Descripción de la Provincia de Tarapacá por William Bollaert", Norte Grande, Santiago, Vol. $1, n^{\circ} 3-4,1975,459-479$.

Llanque Chana, Domingo. "Rol de sacerdotes y médicos nativos en la sociedad aymara", Boletín Instituto de Estudios Aymaras, Chucuito, $\mathrm{n}^{\circ} 20,1985,10-31$.

Lanque Chana, Domingo. "La experiencia cosmológica de dios en la religiosidad aymara". Cristianismo y culturas latinoamericanas. Edic. Paulinas, Santiago, 1992. 45-60.

Martínez, Gabriel. "El sistema de Uywiris en Isluga", Homenaje al Dr. Gustavo le Paige, s.j. Univ. del Norte, Antofagasta, 1976, 255-327. 
Martínez, Gabriel. "Estructuras binarias y terciarias en Pueblo Isluga”, Espacio y Pensamiento. Andes Meridio nales. La Paz, 1989, 109-148.

Marzal, Manuel. La transformación religiosa peruana. Universidad Católica, Lima. 1978.

Marzal, Manuel. El Sincretismo iberoamericano. Universidad Católica, Lima. 1985.

Marzal, Manuel. "Análisis etnológico del sincretismo iberoamericano", Cristianismo y sociedad, Buenos Aires, Vol. 88, 1986, 27-39.

Monast, Jacques. Los indios aymaraes: Evangelizados o solamente bautizados?. Buenos Aires. 1972.

Monast, Jacques. “L'univers religieux des aymaras”, Kerygma, Ottawa., Vol. 19, n 45, 1985, $157-168$.

Montes Ruiz. F. Simbolismo y personalidad aymaras en la historia. Tesis en Psicología. Universidad Católica, La Paz. 1984.

Montes Ruiz, F. La Mascara de piedra. Simbolismo y personalidad aymara en la historia. La Paz. Edit. Quipus. 1986.

Ochoa, Victor. "Cosmovisión Aymara", Boletín del Instiluto de Estudios Aymaras, Chucuito, n 1, 1978, p. 22$32 ; n^{\circ} 2,1978$, p. 25-39 y n'3,1978, 1-13.

Olmos, Olaf \& Pérez, Eduardo. "Actividades productivas y el computo del tiempo entre los aymaras del norte de Chile". TER. lquique. Documento de Trabajo. Ms.(s/f) 27.

Ortner, Sherry. "On key Symbols", American Anthropologist, Vol. 75. 1973. 1338-1346.

Tudela, Patricio. Transformación Religiosa y Desintegración de la Comunidad Aymara Tradicional en el Norte de Chile. Bonn, Holos Verlag, 1992.

Tudela, Patricio. "Cambio Religioso y Revitalización de la Comunidad entre los Aymaras de Arica (19601990)", Nütram, Conversación, Palabra. Historia. Año IX, n 33, 1993, 15-48.

Tudela, Patricio. "Chilenización y cambio ideológico entre los aymaras de Arica (1883-1930). Intervención religiosa y secularización", Revistra Chilena de Aniropología, Santiago, n 12, 1993-94, 201-231.

Yaranga, Abdón. “La divinidad lllapa en la región andina”, América Indígena, México. Vol. 39, n 4, 1979. 697-720. 